\title{
KNOWLEDGE, ATTITUDE, AND PRACTICE REGARDING COVID-19 AMONG PRIMARY SCHOOL STUDENTS IN KEDAH, MALAYSIA: A CROSS-SECTIONAL STUDY
}

\author{
Charles Ganaprakasam¹, Syeda Humayra², Kalaivani Ganasegaran ${ }^{3}$, Elillarasi Kuppusamy ${ }^{4}$ and Barani \\ Karikalan ${ }^{5}$ \\ ${ }^{1}$ Department of Educational Psychology and Counselling, University of Malaya, 50603 Kuala Lumpur, Malaysia. \\ ${ }^{2}$ Faculty of Medicine, University of Cyberjaya, Persiaran Bestari, Cyber 11, 63000 Cyberjaya, Selangor, Malaysia. \\ ${ }^{3,4}$ Department of Mass Communication, School of Management \& Business, Manipal International University, 71800 \\ Negeri Sembilan, Malaysia. \\ ${ }^{5}$ Faculty of Medicine, Perdana University-RCSI, Wisma Chase Perdana, Kuala Lumpur, Malaysia.
}

Corresponding author: Syeda Humayra

Email: syedahumayra@gmail.com

\begin{abstract}
Since, children are affected by the coronavirus in the same way as adults, examining the children's knowledge, attitude, and practice (KAP) on COVID-19 would help in building a pandemic-resilient society. Therefore, the present study aims to investigate the knowledge, attitude, and practice regarding COVID-19 among primary school students. This online, cross-sectional study was conducted from May 18 to 20, 2021 among students aged 9 to 12 years old and having access to WhatsApp messenger on their smartphones. The study participants were selected from 17 primary schools in Kedah, Malaysia by convenience sampling, and the Google form invitation link was shared by the schools' guidance and counselling teachers. Analysis revealed higher females (53\%) and majority aged 12 years (27.8\%) out of 1207. 56\% of respondents possessed good knowledge on COVID-19 (M=4.21, SD=1.16) with $73.75 \%$ overall correct responses. Children demonstrated positive attitudes $(M=3.64, S D=0.67)$ but had a higher perceived risk of becoming infected with COVID-19 $(M=3.60, S D=1.23)$. For practices, low scores were discovered on avoid visiting crowded places $(M=2.51, S D=1.22)$. Knowledge has a significant effect on children's attitudes (Beta $=0.17, p<0.001)$ and practices (Beta $=0.25, p<0.001)$. Comparatively, females scored lower COVID-19 knowledge than males (Beta= $-0.01, p=0.65)$. While age was significantly associated with increased knowledge (Beta $=0.13, p<0.001)$, whereof, year 6 students (12 years; $M=4.69, S D=1.23$ ) scored the highest. Since knowledge is a critical tool in comprehending any phenomenon, and influencing one's attitude and practice towards it, much effort is warranted to enhance the effectiveness of government strategies and mitigate the COVID-19 outbreak.
\end{abstract}

Keywords: Knowledge, Attitude, Practice, KAP, COVID-19, Children

\section{INTRODUCTION}

Healthcare crises such as virus outbreaks are not really unprecedented phenomena in Malaysia. Back in the 1990's, Nipah virus (NiV) was first detected in Malaysian population between October 1997 to May 1999. It subsequently spread to several regions across the country and headed south towards Singapore due to the movement of infected pigs ${ }^{1}$. The NiV outbreak damaged the billion dollar worth pig farming industry in Malaysia, and caused 105 human deaths giving rise to a mortality rate of nearly $40 \%{ }^{2}$. Consistent efforts by Malaysian virologist, Dr Kaw Bing Chua, in collaboration with various international scientists around the world ultimately led to the eradication of this destructive outbreak in Malaysia ${ }^{3}$. It is crucial to acknowledge the combined strategic and effective measures of the Malaysian government and healthcare authorities, back in those days that successfully curbed the disease outbreak ${ }^{2}$.

In 2019, the Coronavirus infectious diseases (COVID-19) from Wuhan, China, shattered the entire nation's healthcare system and disrupted the everyday lives of all human beings. As of writing, the SARS-CoV-2 has infected nearly $171,782,908$ people and caused 3,698,621 deaths globally ${ }^{4}$. National healthcare providers across the world are facing countless adversities due to this pandemic; while, the situation in developing countries is far more challenging. In Malaysia, the incidence of COVID-19 is increasing rapidly, for instance, newly infected cases recorded during the data collection of this study (18 May20 May 2021) was 12,881 precisely.

Thereby, various ongoing efforts are currently being administered by the government to mitigate the propagation of disease and tackle this healthcare emergency. Continuation of Movement Control Order (MCO) in different phases, increased budget allocation for healthcare system from RM 30.6 billion in 2020 to RM 31.9 billion in 2021, and special allowance packages for the healthcare frontliners are some of the major initiatives ${ }^{5}$. However, eliminating 
the COVID-19 disease is an arduous task that may require ample time and resources.

Government has implemented several strategies such as nationwide closure of all educational institutions including primary to tertiary sectors to control the COVID-19 transmission. Currently, online learning seems to be an effective alternative during the school closure period due to pandemic. However, schools cannot remain closed for an indefinite time period as it plays a significant role in the child's academic development. Simultaneously, policymakers also need to evaluate and enforce specific protocol before reopening schools to prevent higher level of community transmission. Indeed, out of 17 new COVID-19 clusters in the midst of April, 2021, four were detected in the education sectors involving two schools ${ }^{6}$. Recently, the concern has been increasing dramatically and needs urgent attention due to the rising number of COVID-19 deaths including children in Malaysia ${ }^{7}$.

Besides, due to the unavailability of COVID-19 vaccines for children ${ }^{8}$, the government has to consider school reopening decision meticulously. In the current scenario, the most practical way to overcome this problem is by educating children on COVID-19 and reducing the risk of infection spread. Educators may be able to plan and implement effective strategies by identifying and ensuring that the students have adequate knowledge regarding COVID-19.

Moreover, the COVID-19 pandemic has made many people inquisitive as they want to comprehend the phenomenon better and protect their loved ones. Several questions have been revolving around people's mind such as how does the virus spread? What are the symptoms? Who is highly vulnerable to the COVID-19 infection? What can we do? Research on people's perception on COVID-19 helps the policymakers and healthcare authorities to advance the ongoing efforts to curb the disease from spreading vigorously. Since, children are affected by the coronavirus in the same way as any other age group ${ }^{9}$, examining children's level of knowledge, attitude, and practice on COVID19 would help in planning appropriate strategies to build a pandemic-resilient society. As stated by Masoud et al., future study with different populations is needed to mitigate the outbreak of COVID-19 and to implement active, innovative strategies ${ }^{10}$.

Students' knowledge, attitude, and practice (KAP) on COVID-19 is an important element in determining the community's readiness to understand and practice the Standard Operation Procedure (SOP) guidelines introduced by the government. Furthermore, the KAP research has a significant contribution in developing proper prevention and intervention strategies as well as educational, health and safety related programs to battle the COVID-19 pandemic.

\section{LITERATURE REVIEW}

As knowledge, attitude and practice, collectively, plays a pivotal role in ensuring these efforts and managing the disease transmission, thereby, several research involving COVID-19 related KAP has been recently carried out to utilize the valuable information for a greater good of the community. The research on knowledge, attitude and practice regarding COVID-19 has expanded to many countries including Malaysia ${ }^{11,}{ }^{12,}{ }^{13}$, Singapore ${ }^{14}$, Bangladesh ${ }^{15,}{ }^{16}$, China, India, and Pakistan ${ }^{17}$, Egypt $^{18}$, Hong Kong ${ }^{19}$, Iran ${ }^{20}$, Palestine ${ }^{21}$, South Korea $^{22}$, Sudan ${ }^{23}$, and Uganda ${ }^{24}$, Syria ${ }^{25}$, Nepal ${ }^{26}$, and Northeast Ethiopia ${ }^{27}$, as an effort towards improving the communication and intervention in response to the pandemic ${ }^{10}$.

In the Malaysian context, majority of the studies focused on general population including young adults and elderly ${ }^{13}, 28$ and university students ${ }^{29}$. Although, one recent study with a younger age group (15 years and above) aimed to find the KAP of social distancing during COVID-19 outbreak $^{30}$. Previous studies associated individuals with lower educational level having reduced COVID-19 knowledge ${ }^{22,29}$; thus, making them more vulnerable and more likely to develop negative attitude and behaviour ${ }^{22}$.

Studies conducted among the general public ${ }^{12,13}$ and medical students in Malaysia ${ }^{11}$ shows that most of the respondents possessed good level of knowledge and showed positive attitude on practicing the precautionary steps to prevent infection. However, wearing masks is reportedly less common among the Malaysian population as observed by Azlan et al ${ }^{13}$. Several existing studies reported that most of the people across the world are equipped with good level of knowledge on COVID-19 and practice appropriate preventive behaviour ${ }^{14,21,22,24,31}$. For example, Banik et al. found that Bangladeshis possessed a higher level of knowledge on COVID-19; whereof females scored higher than male respondents ${ }^{31}$. Indeed, there are mixed findings regarding the knowledge on COVID-19 related to gender differences. Contradict to previous study which demonstrated higher knowledge on COVID-19 among females ${ }^{13}, 23,31,32$, several other studies indicated that male possessed greater COVID-19 knowledge $17,24,26$.

Referring back to the people's knowledge, attitude and practice on COVID-19, a larger number of studies revealed that public has very poor knowledge on COVID-19 ${ }^{19,27}$, and fair level of COVID-19 knowledge among people in Nepal and Sudan 10, 23, 25, 26. Overall, it can be concluded that people's knowledge on certain issues particularly during the public health 
emergencies can significantly impact the efforts initiated by the government to curb the COVID19 pandemic.

Very limited number of studies were carried out to investigate KAP on COVID-19 among primary school students. Existing evidence among primary schools in China (7-11 years old) indicated that optimistic students have good knowledge, attitudes, and practices compared to depressive students ${ }^{33}$. Additionally, a finding from a preprint article ${ }^{34}$ revealed that $74.1 \%$ out of 7,377 students from primary and secondary schools in China possessed good level of knowledge on COVID-19. Wen et al. further claimed that primary school students (9-12 years old) scored higher than vocational students in terms of knowledge on COVID-1934. Indeed, both existing evidence indicated that females possessed a higher level of knowledge on COVID19 compared to males.

In local context, this is the very first study in Malaysia involving children. To address the existing gaps in literature, the current study investigated the level of knowledge, behaviour, and attitude towards COVID-19 among primary school students and identified the influence of knowledge on practicing COVID-19 precautionary guideline and attitude. This study also investigated the gender and age differences related to COVID-19 knowledge to identify the vulnerable group of students during this destructive outbreak. As mentioned earlier, this study may help to improve the targeted management and health education of COVID-19 among school students.

\section{METHODS}

Since survey is a distinctive method to gather information from a larger sample concerning the knowledge of a certain issue or topic ${ }^{35}$, the current study utilized a cross-sectional design to investigate the knowledge, attitude, and perception towards COVID-19 among primary school students in Malaysia.

\section{Participants}

The respondents of this study were selected from 17 primary schools in Kedah, Malaysia by convenience sampling. Students aged between 9-12 years old, having access to WhatsApp messenger on their smartphones were eligible to participate in this study. The total population of primary school students was approximately 12,457. Krejcie and Morgan sample decision model was used to determine the sample size for this study ${ }^{36}$. According to the sample size determination table, the minimum sample size required for this study was 375; however, after considering a survey response rate of $40 \%$, the estimated sample size was calculated to be 938 .
Nonetheless, the researchers recruited 1207 participants due to the increased number of responses, and to strengthen the study analysis.

\section{Procedure}

The data collection occurred over 3 days (May 18 to 20, 2021). At the time of data collection, Malaysia recorded a drastic escalation in the COVID-19 infection rate. Thereby, the current study opted for an online survey tool, whereby, Google forms were administered to gather all data. Researchers have utilized every possible way to communicate with the school administration and to run the data collection process smoothly. Participants for this study were invited through the assistance of every schools' guidance and counselling teachers. The survey invitation contained general information on the study including its objective, outcome, consent statement from parents, and contact information of principal investigator for any study-related queries. Prior permission was also obtained from the schools' administrative departments. The respondents were also informed about data confidentiality and voluntary participation. The invitation link was shared through WhatsApp messenger since Malaysians are one of the largest WhatsApp users globally. In fact, previous studies in Malaysia have also emphasized the usage of WhatsApp for educational purposes ${ }^{37}, 38$, therefore, the questionnaire link was disseminated through WhatsApp mobile application on April 18, 2021.

\section{Measurement}

Survey questionnaire utilized in this research was adopted from Lee et al., ${ }^{22}$ and followed similar measurement scale. However, it was originally developed by Zhong et al., an online, crosssectional study to investigate the knowledge, attitude, and practice on COVID-19 among Chinese residents ${ }^{39}$. Recently, other researchers have also used this tool for similar KAP studies on COVID-19 in Malaysian population ${ }^{13,28}$. Due to the ease of students' better understanding, the survey instrument used in this study was delivered in simple English language, and had four main components. Section one comprised of six items concerning the knowledge on COVID-19 including clinical characteristics of the virus, method of transmission, and disease prevention. Each item has three options namely 'Yes', 'No', and 'Don't know'. Every correct answer assigned one point and an aggregated score was calculated (range 0-6) with a higher score indicating better knowledge. Section two consisted of three items concerning the attitude on COVID-19 and each of the items was measured using 4-point Likert scale namely, '1=never, 2=sometimes, 3=often, 4=always". Three items in this section measured preventive actions and social distancing. Section three 
contained two questions concerning the perceived risk of COVID-19 infection which focus on respondents' belief on possibility of infection and perceived severity if they get infected. Responses were rated on a 5-point Likert scale, with "1=very low, $3=$ neither low nor high, and $5=$ very high". Another two items under section three focusing on the perceived precautionary behaviour related to COVID-19 with 4-point Likert scale from ' $1=$ not at all to 4=extremely. Lastly, section four in this study consisted of two demographic questions related to the gender and age of respondents. Content and construct validity were carried out to test the validity and reliability of this research instrument. The study questionnaire was reviewed by two experts in the field of public health. Items with a factor loading of greater than 0.30 was considered acceptable. The reliability analysis for the three domains of questionnaire were $0.76,0.84$, and 0.82 respectively. While the overall Cronbach's alpha coefficient for knowledge, attitude and practice was 0.85, indicating acceptable internal consistency and reliability (Table 1 ).

\section{Statistical Analysis}

Data was analysed using the IBM Statistical Package of Social Sciences (SPSS) version 25.0. Data exploration and cleaning was carried out. Then, descriptive statistics was applied by reporting all quantitative variables either as mean (M), standard deviation (SD), and frequencies (percentage \%). Simple linear regression was performed to investigate the relationship between COVID-19 knowledge, attitude and practices. Residual normality and multicollinearity were checked. Multiple regression analysis was conducted to find the differences in gender and age in regard to the COVID-19 knowledge. The level of significance was set at $\mathrm{P}$-value less than 0.05 .

\section{RESULTS}

Firstly, the outliers in this study were identified using a boxplot. There were no extreme outliers present in knowledge, attitudes and practices, thus, no outliers were removed. Overall, responses from 1207 samples deemed valid with no missing or incomplete information, and were considered in the final analysis. Sociodemographic characteristics showed that female students (53\%) outnumbered the males (47\%). Meanwhile in terms of age, majority $(27.8 \%)$ of the respondents were 12 years, followed by 10 years $(25.9 \%), 11$ years $(24 \%)$, and 9 years $(22.2 \%)$.
Knowledge, attitudes, and practices concerning COVID-19

$56 \%$ of the respondents possessed good knowledge on COVID-19 $(M=4.21, S D=1.16)$, with $73.75 \%$ overall correct response rate for the knowledge item. Respondents appeared to be knowledgeable about the main clinical symptoms of COVID-19 (84.3\% correct responses), and $80.9 \%$ respondents correctly mentioned that wearing medical masks can prevent COVID-19 infection (Table 2).

In terms of attitude, overall, participants showed positive attitudes with mean value of 3.64 $(S D=0.67)$. Respondents perceived risk of becoming infected with COVID-19 was higher $(M=3.60, S D=1.23)$ as compared to the perceived severity of COVID-19 infection $(M=3.53$, $S D=1.33)$. Meanwhile, for efficacy beliefs, respondents believed that practicing personal hygiene such as wearing facial masks and using hand hygiene is highly effective $(M=3.72$, $\mathrm{SD}=0.64)$ compared to social distancing such as avoiding crowded places $(M=3.68, S D=0.70)$.

For practices of preventive behaviour, most of the respondents scored average and followed the preventive measures such as wearing facial masks $(M=3.43, S D=0.76)$, as well as frequent hand washing and the regular use of hand sanitizer $(M=3.34, S D=0.78)$. However, low scores were discovered on avoid visiting crowded places $(M=2.51, S D=1.22)$.

\section{Relationship between COVID-19 knowledge, attitude and practices}

Simple linear regression was conducted in order to investigate the influence of COVID-19 knowledge on the respondents' attitude and practice. A few assumptions were performed such as normality of the residuals and linearity. The first model was conducted to determine the relationship between COVID-19 knowledge and attitudes. The model was significant $F(1,1205)$ $=35.90, p<0.001$. $R^{2}$ was 0.03 , indicating that $3 \%$ of variance in attitudes can be explained by the knowledge towards COVID-19. Results also showed that knowledge has a significant effect on the children's attitudes (Beta=0.17, $p<0.001$ ) (Table 4).

The second regression model was conducted to determine the relationship between COVID-19 knowledge and practices. The model was significant $F(1,1205)=78.55, p<0.001 . R^{2}$ was 0.06 , indicating that $6 \%$ of the variance in practices can be explained by knowledge towards COVID-19. Results further revealed that knowledge has a significant effect on practices (Beta $=0.25, p<0.001)$ (Table 3). 
Table 1: Exploratory factor analysis and internal consistency to present the construct validity and reliability analyses of questionnaire on COVID-19 knowledge, attitude, and practice

\begin{tabular}{lcccc}
\hline & & Factor loading & Reliability \\
\cline { 2 - 4 } Knowledge & Knowledge & Attitude & Practice & Cronbach's Alpha \\
& & & & 0.76
\end{tabular}

B1: The main clinical symptoms of

COVID-19 are fever, fatigue, dry

cough, and myalgia

B2: There currently is no effective cure for COVID-2019, but early

symptomatic and supportive

treatment can help most patients recover from infection.

B3: Not all persons with COVID-

2019 will develop severe cases.

Only those who are elderly have

chronic illnesses are more likely to be in severe cases.

B4: Eating or contacting wild animals would result in infection

by the COVID-19 virus.

B5: The COVID-19 virus spreads via respiratory droplets of infected individuals.

B6: Ordinary residents can wear general medical masks to prevent 0.715 infection by the COVID-19 virus. Attitude

C1: What do you think is the possibility of your COVID-19 0.719

infection?

C2: What do you think will be the severity if COVID-19 infects you?

C3: Practicing personal hygiene such as wearing facial masks and hand hygiene'

C4: Social distancing such as avoiding crowded places

Practice

D1: Wearing facial masks

D2: Wash hands frequently and use hand sanitizer 
Table 2: Response of knowledge on COVID-19 ( $\mathrm{N}=1207)$

No. Knowledge Items

Correct Incorrect $\begin{gathered}\text { Do not } \\ \text { know }\end{gathered}$

B1 The main clinical symptoms of COVID-19 are fever, fatigue, dry cough, and myalgia.

$\begin{array}{ccc}1018 & 168 & 21 \\ (84.3 \%) & (13.9 \%) & (1.7 \%)\end{array}$

There currently is no effective cure for COVID-2019, but early

B2 symptomatic and supportive treatment can help most patients recover from infection.

912

$(75.6 \%)$

167

$(13.8 \%)$

128

$(10.6 \%)$

Not all persons with COVID-2019 will develop severe cases. Only

B3 those who are elderly have chronic illnesses are more likely to be in severe cases.

B4

Eating or contacting wild animals would result in infection by the COVID-19 virus.

B5

The COVID-19 virus spreads via respiratory droplets of infected individuals.

B6

Ordinary residents can wear general medical masks to prevent

$\begin{array}{ccc}736 & 383 & 88 \\ (61.0 \%) & (31.7 \%) & (7.3 \%) \\ 730 & 356 & 121 \\ (60.5 \%) & (29.5 \%) & (10.0 \%) \\ 968 & 169 & 70 \\ (80.2 \%) & (14.0 \%) & (5.8 \%) \\ 977 & 170 & 60 \\ (80.9 \%) & (14.1 \%) & (5.0 \%)\end{array}$
infection by the COVID-19 virus.

Table 3: Response of knowledge, attitudes and practices on COVID-19

\begin{tabular}{lrrr}
\hline Variable & Range & $M$ & SD \\
\hline Knowledge & & & \\
Knowledge score & $0-6$ & 4.43 & 1.32 \\
Attitudes & & &
\end{tabular}

Perceived Risk of COVID-19 infection

What do you think is the possibility of your COVID-19 infection?

What do you think will be the severity if COVID-19 infects you?

$1-5 \quad 3.60 \quad 1.23$

Efficacy beliefs

Practicing personal hygiene such as wearing facial masks and hand $1-4 \quad 3.72 \quad 0.64$ hygiene'

Social distancing such as avoiding crowded places $\quad \begin{array}{lll}1-4 & 3.68 & 0.70\end{array}$

Practices

Practices of preventive behaviour

Wearing facial masks

Wash hands frequently and use hand sanitizer

Avoid visiting crowded places

$\begin{array}{lll}1-4 & 2.51 & 1.22\end{array}$

${ }^{*} M$ : means and SD: standard deviation

Gender and age differences in COVID-19 knowledge

The differences in gender and age in relation to the COVID-19 knowledge were examined by using multiple regression analysis. Prior to analyzing the regression model, a few assumptions were performed such as residual normality and multicollinearity (attached in Appendix). After 
checking all possible assumptions met, the regression for two factors (age and gender) were suitable to be conducted. The regression model was significant $F(2,1204)=10.744, p<0.001 . R^{2}$ was 0.018 , indicating that $1.8 \%$ of variance in knowledge towards COVID-19 can be explained by both these demographic characteristics. Analysis showed that females scored lower knowledge level on COVID-19 than male respondents (Beta $=-0.01, p=0.65)$, however no significant differences were established among both gender in regards to COVID-19 knowledge (Table 5).
The results also revealed that age has a significant effect on COVID-19 knowledge (Beta $=0.13$, $p<0.001)$, wherein students from higher academic level and advancing age showed better knowledge, such as year 6 (12 years old; $M=4.69$, $S D=1.23$ ) possessed good level of knowledge, followed by year 5 (11 years old; $M=4.53, S D=1.31)$, year 4 (10 years old; $M=4.26$, $\mathrm{SD}=1.42$ ), and year 3 (9 years old; $M=4.26$, $\mathrm{SD}=1.29)$ (Table 4).

Table 4: COVID-19 knowledge determinants of attitude and practices

\begin{tabular}{lccccccc}
\hline & & B & Std. Error & Beta & t-statistic & P-value & $\mathbf{R}^{2}$ \\
\hline Model 1 & Constant & 3.25 & 0.07 & & 48.85 & $<0.001$ & 0.03 \\
& & 0.09 & 0.01 & 0.17 & 5.99 & $<0.001$ & \\
& & & & & & & \\
Model 2 & Constant & 2.54 & 0.07 & & 38.47 & $<0.001$ & 0.06 \\
& & 0.13 & 0.01 & 0.25 & 8.86 & $<0.001$ & \\
\hline
\end{tabular}

Table 5: Gender and age determinants of COVID-19 knowledge

\begin{tabular}{lccccc}
\hline & B & Std. Error & Beta & $t$-statistic & P-value \\
\hline Constant & 6.09 & 0.36 & & 16.79 & $<0.001$ \\
Gender (v. male) & & & & \\
Female & -0.03 & 0.08 & -0.01 & -0.45 & 0.65 \\
Age & -0.16 & 0.03 & -0.13 & -4.62 & $<0.001$ \\
\hline
\end{tabular}

\section{DISCUSSION}

It was initially predicted that younger children do not play a major role in disease transmission, however, as newly modified strains are being identified and adults are getting vaccinated, it increases the possibility of children getting infected and bringing the virus home. In Michigan, the incidence of COVID-19 cases was highest among children getting exposed to the B.1.1.7 variant, and the escalation was right after the schools reopened. Similar observations regarding children were also noted in the UK and Europe $^{40}$. While asymptomatic cases in children have also been reported; a recent study published in the Lancet revealed a greater proportion of children having mild disease or asymptomatic infection ${ }^{41}$. This is quite alarming and risky for all population who comes in close contact to the asymptomatic COVID-19 cases.
Therefore, government officials need to strategize and enforce effective health programs for increasing infection control practice and engaging public awareness in order to tackle the rising number of cases.

Children are the building blocks of society who require adequate health literacy, positive attitude and preventive behaviour towards COVID-19. It is important to assess this specific population as they may be less knowledgeable and more likely to absorb the false information spread via internet or social media. Thus, this research aimed to investigate the KAP among Malaysian primary school students.

Study findings revealed that the primary school students have adequate knowledge about COVID19, its clinical characteristics, mode of transmission, and prevention. The respondents' 
perceived risks and efficacy beliefs related to their attitudes were also high. Majority of the children have been practicing preventive behaviour but avoiding or visiting crowded places was less frequently practiced, which indicates the need of additional safety measures to monitor and resolve this issue. It was also found that knowledge is significantly associated with the respondents' practice and attitude. This shows that knowledge plays an active role in improving the preventive behaviour, as similar correlations were also interpreted in other KAP studies22, 28, 42. Even with the good level of knowledge in children, there was notable misinformation regarding the COVID-19 virus transmission through eating or contact with wild animals, as $60.5 \%$ of the respondents had the misconception that this statement was correct. This particular finding is consistent with another Malaysian study, whereof $29.2 \%$ of the respondents were unaware about the information ${ }^{13}$. Hence, it is recommended to the health authorities to disseminate COVID-19 related information in a more precise and simplified way for better understanding. It is also advisable to the parents as well as teachers to help guide the children look into evidence-based information from legit sources, and not solely rely on the internet and/or forwarded messages or posts on social media.

In terms of sociodemographic factors, no significant difference was noted concerning gender. However, male students showed higher level of knowledge in comparison to females. This finding was contradictory to some of the previous studies that reported males having lower COVID-19 based knowledge ${ }^{13}, 22,28,33$. Although higher age and level of education were significantly associated with increased knowledge, and was found to be consistent across all studies. The disparities could be due to differences in the learning and cognitive capability among children, parental supervision, etc. Furthermore, as mental health problems have been previously linked to lower KAP scores in primary school students ${ }^{33}$, it could also be a possible factor accountable for these differences.

\section{CONCLUSION}

Since knowledge is a critical tool in comprehending any phenomenon, and influencing one's attitude and practice towards it, much effort is warranted to enhance the effectiveness of strategies implemented by the current government and to mitigate the outbreak of COVID-19.

Although this is among the first studies conducted among primary schools in Kedah, Malaysia, the current study holds its own limitations. First, considering the nature of the problem being investigated, generalization of the results should be done with utmost caution considering that the targeted sample was derived only from one state in Malaysia. Although the sample size was relatively huge, but all respondents were from the primary schools located in Kedah. Further work needs to be carried out using larger samples across the country. Second, regarding the level of knowledge, we did not identify the source of knowledge, whether it was from social media, television programs, media reports or school activities. Identifying the relevant platform might help in optimizing the deliverance of COVID-19 related information. Last but not the least, social desirability and introspective ability might influence the participants' responses in self-administered questionnaires so qualitative strategies such as interviews can be utilized to collect holistic information. It is also recommended to conduct cohort studies to explore the causal association between knowledge, attitude, and practice.

\section{Acknowledgements}

Foremost, the authors would like to express a heartfelt gratitude to all the Primary Schools in Kedah and the Students for their voluntary participation in this study. Second and most importantly, the Guidance and Counselling Teachers for their great assistance in the survey invitation and data collection phase. Last but certainly not the least, special thanks to the Psychology Research Team, Malaysia for their valuable support and constructive comments.

\section{Ethics declarations}

Prior permission was obtained from the schools and parents. The data anonymity was ensured. Consent for publication was also taken.

\section{Conflict of interest}

There is no conflict of interest for publishing this study.

\section{Funding}

Funding is not applicable to this study.

\section{Author contributions}

All authors made significant contribution to the manuscript. Final version of paper was reviewed and approved for submission by all authors.

\section{REFERENCES}

1. Chua KB. Nipah virus outbreak in Malaysia. J Clin Virol 2003; 26(3):265275. https://doi.org/10.1016/s13866532(02)00268-8

2. Looi LM, Chua KB. Lessons from the Nipah virus outbreak in Malaysia. Malays 
J Pathol 2007; 29(2):63-67

3. Chua KB. The discovery of Nipah virus: A personal account. Neurol Asia 2004; 9:59-63

4. WHO. WHO coronavirus disease (COVID19) dashboard with vaccination data [Internet]. World Health Organization; 2021. [Updated 2021 May 20; cited 2021 May 20]. Available from: https://covid19.who.int/

5. Poo C. Budget 2021: Healthcare measures welcomed but fall short [Internet]. The Edge Markets; 2020. [Updated 2020 Nov 16; cited 2021 May 28]. Available from: https://www.theedgemarkets.com/artic le/budget-2021-healthcare-measureswelcomed-fall-short

6. Kaus J. Covid-19: 17 new clusters, four linked to education sector [Internet]. The Star; 2021. [Updated 2021 Apr 30; cited 2021 May 29]. Available from: https: / /www.thestar.com.my/news/nati on/2021/04/30/covid-19-17-new-

clusters-four-linked-to-education-sector

7. Sipalan J. Malaysia warns of rising number of COVID-19 deaths, cases among children [Internet]. The Thomson Reuters; 2021. [Updated 2021 June 4; cited 2021 Jun 10]. Available at: https: / / news.trust.org/item/2021060403 4312-in4cc/

8. Lambert JA, Trott K, \& Baugh RF. An analysis of $\mathrm{K}-12$ school reopening and its impact on teachers. J Prim Care Community Health 2020; 11:2150132720967503.

https://doi.org/10.1177/2150132720967 503

9. Saleem H, Rahman J, Aslam N, Murtazaliev S, \& Khan S. Coronavirus disease 2019 (COVID-19) in children: vulnerable or spared? A systematic review. Cureus 2020; 12(5): e8207. https://doi.org/10.7759/cureus.8207

10. Masoud AT, Zaazouee MS, Elsayed SM, Ragab KM, Kamal EM, Alnasser YT, et al. KAP-COVID GLOBAL: a multinational survey of the levels and determinants of public knowledge, attitudes and practices towards COVID-19. BMJ open 2021; 11(2):1-9. https: / /doi.org/10.1136/bmjopen-2020043971

11. Abd Rahim IS, Roslan MB, Zaini NN, Kasim NS, Yazid MI, Pasi $\mathrm{H}$, et al.
Knowledge, attitudes and practices towards covid-19 among medical students in International Islamic University Malaysia: an online crosssectional study. IIUM Med J Malays 2021; 20(2):103-111

https://doi.org/10.31436/imjm.v20i2.16 86

12. Chang $C T$, Lee $M$, Lee JCY, Lee NCT, Ng TY, Shafie AA, et al. Public KAP towards COVID-19 and antibiotics resistance: a Malaysian survey of knowledge and awareness. Int $J$ Environ Res Public Health 2021; 18(8):3964. https://doi.org/10.3390/ijerph18083964

13. Azlan AA, Hamzah MR, Sern TJ, Ayub SH, Mohamad E. Public knowledge, attitudes and practices towards COVID-19: a crosssectional study in Malaysia. Plos One 2020; 15(5):e0233668. https://doi.org/10.1371/journal.pone.02 33668

14. Yap J, Lee VJ, Yau TY, Ng TP, \& Tor P-C. Knowledge, attitudes and practices towards pandemic influenza among cases, close contacts, and healthcare workers in tropical Singapore: a crosssectional survey. BMC Public Health 2010;

$10(1): 1-$

8. https://doi.org/10.1186/1471-2458$10-442$

15. Ferdous MZ, Islam MS, Sikder MT, Mosaddek ASM, Zegarra-Valdivia JA, \& Gozal D. Knowledge, attitude, and practice regarding COVID-19 outbreak in Bangladesh: an online-based crosssectional study. Plos One 2020; 15(10):e0239254.

https://doi.org/10.1371/journal.pone.02 39254

16. Rana MM, Karim MR, Wadood MA, Kabir $M M$, Alam MM, Yeasmin F, \& Islam MR. Knowledge of prevention of COVID-19 among the general people in Bangladesh: A cross-sectional study in Rajshahi district. Plos One 2020; 15(12): e0243410.

https://doi.org/10.1371/journal.pone.02 43410

17. Qalati SA, Ostic D, Fan M, Dakhan SA, Vela EG, Zufar Z, et al. The general public knowledge, attitude, and practices regarding COVID-19 during the lockdown in asian developing countries. Int Q Community Health Educ 2021; 1 10.

https://doi.org/10.1177/0272684X21100 4945 
18. Kasemy ZA, Bahbah WA, Zewain SK, Haggag MG, Alkalash SH, Zahran E, et al. Knowledge, attitude and practice toward COVID-19 among Egyptians. J Epidemiol Glob Health 2020; 10(4):378-385. https: / / doi.org/10.2991/jegh.k.200909. 001

19. Wong CL, Chen J, Chow KM, Law BMH, Chan DNS, So WKW, et al. Knowledge, attitudes and practices towards COVID19 amongst ethnic minorities in Hong Kong. Int J Env Res Public Health 2020; 17(21):1-13.

https://doi.org/10.3390/ijerph17217878

20. Moradzadeh R, Nazari J, Shamsi M, \& Amini S. Knowledge, attitudes, and practices toward coronavirus disease 2019 in the central area of Iran: a population-based study. Front Public Health 2020; 8:599007. https: / /doi.org/10.3389/fpubh.2020.599 007

21. Qutob N, \& Awartani F. Knowledge, attitudes and practices (KAP) towards COVID-19 among Palestinians during the COVID-19 outbreak: A cross-sectional survey. PloS One 2021; 16(1):1-11. https://doi.org/10.1371/journal.pone.02 44925

22. Lee $M$, Kang B-A, \& You M. Knowledge, attitudes, and practices (KAP) toward COVID-19: a cross-sectional study in South Korea. BMC Public Health 2021; 21(1):1-10.

https://doi.org/10.1186/s12889-02110285-y

23. Hezima A, Aljafari A, Aljafari A, Mohammad A, \& Adel I. Knowledge, attitudes, and practices of Sudanese residents towards COVID-19. East Mediterr Health J 2020; 26(6):646-651. https://doi.org/10.26719/emhj.20.076

24. Okello G, Izudi J, Teguzirigwa S, Kakinda $A$, \& Van Hal G. Findings of a crosssectional survey on knowledge, attitudes, and practices about COVID-19 in Uganda: implications for public health prevention and control measures. Biomed Res Int 2020; 2020:1-8. https: / /doi.org/10.1155/2020/5917378

25. Al ahdab S. A cross-sectional survey of knowledge, attitude and practice (KAP) towards COVID-19 pandemic among the Syrian residents. BMC Public Health 2021;

21:1-7. https://doi.org/10.1186/s12889-02110353-3
26. Devkota HR, Sijali TR, Bogati R, Clarke A, Adhikary P, \& Karkee R. How does public knowledge, attitudes, and behaviors correlate in relation to COVID-19? a community-based cross-sectional study in Nepal. Front Public Health 2021; 8:589372.

https: / / doi.org/10.3389/fpubh.2020.589 372

27. Gebretsadik D, Gebremichael S, \& Belete MA. Knowledge, attitude and practice toward covid-19 pandemic among population visiting dessie health center for covid-19 screening, northeast Ethiopia. Infect Drug Resist 2021; 14:905-915.

https: / /doi.org/10.2147/IDR.S297047

28. Mehmet N, Al-Abed AA, Gökler ME, Elengoe A, Ünal $E$, \& Mollahaliloğlu $S$. Knowledge, attitudes and practices regarding COVID-19 among the Turkish and Malaysian general populations during lockdown: a cross-sectional online survey. Ethiop J Health Dev 2020; 34(4):243-252

29. Sazali MF, Rahim SSSA, Mohamed MH, Omar A, Pang NTP, Jeffree MS, et al. Knowledge, attitude and practice on COVID-19 among students during the early phase of pandemic in a university in Borneo, Malaysia. J Public Health Res 2021.

https://doi.org/10.4081/jphr.2021.2122

30. Samah AA, Muhammad $M$, Sulaiman $A H$, Harun SR. Knowledge, attitudes, and practice among Malaysian in facing COVID-19 during the implementation of movement control order. 2020. https: / /doi.org/10.21203/rs.3.rs35626/v1

31. Banik R, Rahman M, Sikder MT, Rahman QM, \& Pranta MU. Knowledge, attitudes, and practices related to the COVID-19 pandemic among Bangladeshi youth: a web-based cross-sectional analysis. $J$ Public Health 2021; 1-11. https: / / doi.org/10.1007/s10389-02001432-7

32. Yue S, Zhang J, Cao M, \& Chen B. Knowledge, attitudes and practices of COVID-19 among urban and rural residents in China: a cross-sectional study. J Community Health 2020; 46(2):286-291. https://doi.org/10.1007/s10900-02000877-x 
33. Xue Q, Xie X, Liu Q, Zhou Y, Zhu K, Wu $\mathrm{H}$, et al. Knowledge, attitudes, and practices towards COVID-19 among primary school students in Hubei Province, China. Child Youth Serv Rev 2021; 120:105735. https://doi.org/10.1016/j.childyouth.20 20.105735

34. Wen F, Meng Y, Cao H, Xia J, Li H, Qi H, et al. Knowledge, attitudes, practices of primary and middle school students at the outbreak of COVID-19 in Beijing: a cross-sectional online study. medRxiv 2020.

https: / / doi.org/10.1101/2020.06.29.201 38628

35. Jones TL, Baxter MA, \& Khanduja V. A quick guide to survey research. Ann $R$ Coll Surg Engl. 2013; 95(1):5-7. https://doi.org/10.1308/003588413X135 11609956372

36. Krejcie RV, \& Morgan DW. Determining sample size for research activities. Educ Psychol Meas 1970; 30(3):607610. https://doi.org/10.1177/001316447 003000308

37. Mustafa AS, \& Yaakub R. An experimental approach by using whatsapp for teaching and learning of Bahasa Malaysia to international students at Engineering campus, Universiti Sains Malaysia (USM) due to pandemic of COVID-19. PENDETA: J Malay Lang Edu Lit 2021; 12:1-9. https: / / doi.org/10.37134/pendeta.vol12 .edisikhas.1.2021
38. Sivabalan K, Ali Z. Mobile Instant Messaging as a Collaborative Tool for Language Learning. Int J Lang Educ Appl Linguist 2019; 9(1):99-109. https: / /doi.org/10.15282/ijleal.v9.297

39. Zhong B-L, Luo W, Li H-M, Zhang Q-Q, Liu X-G, Li W-T, et al. Knowledge, attitudes, and practices towards COVID19 among Chinese residents during the rapid rise period of the COVID-19 outbreak: a quick online cross-sectional survey. Int J Biol Sci 2020; 16(10):1745. https://doi.org/10.7150/ijbs.45221

40. Goodman B. Cases in Children Helping the Surge of COVID Variants [Internet]. WebMd Health News; 2021 [Updated 2021 Apr 2; cited 2021 June 20]. Available from: https: / /www.webmd.com/lung/news/20 210402/cases-in-children-helping-surgeof-covid-variants

41. Say D, Crawford N, McNab S, Wurzel D, Steer A, \& Tosif S. Post-acute COVID-19 outcomes in children with mild and asymptomatic disease. Lancet Child Adolesc Health 2021; 5(6):e22-e23. https: / /doi.org/10.1016/s23524642(21)00124-3

42. Papagiannis D, Malli F, Raptis DG, Papathanasiou IV, Fradelos EC, Daniil Z, et al. Assessment of knowledge, attitudes, and practices towards new coronavirus (SARS-CoV-2) of health care professionals in Greece before the outbreak period. Int J Env Res Public Health 2020; 17(14):4925. https: / /doi.org/10.3390/ijerph17144925 